\title{
Nietzsche e Bernhard: viver em tempos de morte de deus... ${ }^{1}$
}

Vilmar Martins ${ }^{2}$

\section{Resumo}

O presente texto reflete sobre a condição humana, motivado por três percepções radicais: a fala de Sileno conforme nos apresenta Nietzsche em $O$ nascimento da tragédia; o interdito do absoluto presente na concepção de Nietzsche de que deus morreu e por fim o diagnóstico da condição humana de acordo com Thomas Bernhard na obra Origem. O objetivo é partir de percepções extremas para assim aproximar-se de condições de possibilidades para bem conviver com nossa condição humana, sustentando a hipótese que o cultivo de si e a formação são elementos capazes de elevar a vida em tempos de morte de deus.

Palavras-chave: Nietzsche; Bernhard; Educação; Valores; Niilismo.

\section{Nietzsche and Bernhard: living in god's time of death...}

\section{Abstract}

The present text reflects on the human condition, motivated by three radical perceptions: Sileno's speech as presented by Nietzsche in The Birth of Tragedy; the prohibition of the absolute present in Nietzsche's conception that God died and finally the diagnosis of the human condition according to Thomas Bernhard in the Book Origin. The objective is to start from extreme perceptions to approach the conditions of possibilities to live well with our human condition, supporting the hypothesis that self-cultivation and formation are elements capable of raising life in times of god's death.

Keywords: Nietzsche; Bernhard; Education; Values; Nihilism.

\section{Nietzsche y Bernhard: vivir en tiempos de muerte de dios ...}

\section{Resumen}

El presente texto refleja sobre la condición humana, motivado por tres percepciones radicales: el habla de Sileno conforme nos presenta Nietzsche en El nacimiento de la tragedia; el interdicto del absoluto presente en la concepción de Nietzsche de que Dios murió y por fin el diagnóstico de la condición humana de acuerdo con Thomas Bernhard en la obra Origen. El objetivo es partir de percepciones extremas para así aproximarse a condiciones de posibilidades para bien convivir con nuestra condición humana, sosteniendo la hipótesis que el cultivo de sí y la formación son elementos capaces de elevar la vida en tiempos de muerte de dios.

Palabras clave: Nietzsche; Bernhard; La educación; Los valores; Nihilismo.

\section{Introdução}

A condição humana, eis o propósito de reflexão deste texto. Longe de pretensões universalistas ou reducionistas do humano parto de diagnósticos para especular esse estado denominado condição humana.

\footnotetext{
${ }^{1}$ Pesquisa financiada com bolsa de doutoramento do CNPq - Conselho Nacional de Desenvolvimento Científico e Tecnológico.

${ }^{2}$ UFSC - Universidade Federal de Santa Catarina. Florianópolis/SC.vilmarmartins@hotmail.com
}

Periódico Horizontes - USF - Itatiba, SP - Brasil - e019038 
$\mathrm{Na}$ esteira da crise ou o agravamento da modernidade e o questionamento da universalidade da razão iluminista, especulo valores que permeiam este ser denominado humano. Valores passíveis de diagnóstico com maior e menor frequência a depender da abordagem, mas nunca um diagnóstico pleno e universalizante.

O móbil deste texto é especular a possibilidade de valores - mesmo diante da ausência de valores ou na presença de valores pessimistas e niilistas. O campo de onde parto com essa reflexão é a educação e a sua possibilidade de formação, compreendida como um agenciamento possível do humano.

Para realizar o objetivo do texto, busco no filósofo Friedrich Wilhelm Nietzsche (18441900) concepções para pensar sobre: valores, cultivo de si e educação, bem como as noções de "morte de deus" e niilismo. Outro cúmplice nesse jogo teórico é o literato Thomas Bernhard (1931-1989) e as reflexões sobre infância e formação que constam em sua obra Origem.

Este texto persegue uma questão: Que valores são possíveis na ausência de valores? Ou, que valores afirmativos são possíveis diante de valores negativos? Para responder essa questão divido minha argumentação em seis partes. Inicialmente com Nietzsche explicito um diagnóstico extremo da condição humana "Não ser, nada ser ou o logo morrer..." para então discorrer que "Deus morreu..."; a partir de Bernhard um novo diagnóstico se apresenta "Nascemos para sofrer...", diante desse quadro especulo que "O que nos resta? Niilismo..."; porém a partir de Nietzsche é possível observar a "Educação, como a transvaloração do niilismo..." para por fim pensar "Valores em tempos de morte de deus...".

\section{Não ser, nada ser ou o logo morrer...}

A primeira provocação para pensar nossa condição humana se encontra na leitura que Nietzsche faz do encontro de Sileno ${ }^{3}$ e Midas $^{4}$, na obra $O$ nascimento da tragédia. O filósofo do martelo narra que depois de muito perseguir Sileno, Midas por fim aprisiona o velho sátiro e obriga o mesmo a responder qual dentre todas as coisas era a melhor, a mais preferível, aquela a qual devemos dedicar nossa existência, qual deve ser nossa busca, ou seja, a razão da existência

\footnotetext{
${ }^{3}$ Um dos seguidores de Dioniso, seu professor e companheiro fiel. O sátiro Sileno é sempre descrito como o mais velho, o mais sábio e o mais beberrão dos seguidores de Dioniso.

${ }^{4}$ Personagem da mitologia grega, rei da Frígia.
}

Periódico Horizontes - USF - Itatiba, SP - Brasil - e019038 
humana, a resposta de Sileno é terrível:

Estirpe miserável e efêmera, filhos do acaso e do tormento! Por que me obrigas a dizer-te o que seria para ti mais salutar não ouvir? O melhor de tudo é para ti inteiramente inatingível: não ter nascido, não ser, nada ser. Depois disso, porém, o melhor para ti é logo morrer (NIETZSCHE, 2007, p.33).

Eis o primeiro diagnóstico, "não ser, nada ser" ou "logo morrer". Segundo Nietzsche esta concepção trágica da existência levou os gregos a saírem de uma teogonia titânica - repleta de horrores e crueldade - em uma lenta transição para uma teogonia olímpica - de júbilo, superação e beleza. Ou seja, dada a miserável condição humana, o grego clássico criou deuses que espelhavam as mais altas glórias possíveis aos humanos, pois a humanização dos deuses olímpicos servia como um espelho transfigurador da capacidade humana de superação.

Desta forma o que temos é a criação de valores ativos de superação diante do absurdo de uma existência fadada a um fim único, pois ao grego clássico estava reservado apenas um lugar: as sombras do Hades, sem a possibilidade de superação metafísica da existência em um Paraíso, Valhalla ou Campos Elíseos. Cabia ao grego aceitar as condições de vida e buscar a imortalidade do nome, pois estava interditado o caminho a eternidade física ou espiritual.

Dois exemplos magníficos desta questão: Homero nos relata na Odisseia (2003) que Aquiles vai à guerra de Troia mesmo sabendo que lá morrerá, pois, o herói grego está ciente que a recompensa da guerra - a morte - seria maior que a vida, pois aquela morte seria a morte do corpo e a imortalidade do nome. O outro exemplo está na llíada (2001), quando Calipso oferece a imortalidade da vida a Ullisses e este sabiamente recusa. A existência sem fim, sem sofrimentos e de puro gozo, proposta pela deusa, não seduz o grego, pois este tinha ciência que uma vivência em tal configuração teria como resultado o tédio, e como bom grego sua busca era a imortalidade do nome e não propriamente a ausência de sofrimento.

Esta imortalidade do nome - mais tarde lida por Foucault como uma estética da existência ${ }^{5}$ - o tornar a vida uma obra de arte, viver como protagonista da própria epopeia. Em

\footnotetext{
${ }^{5}$ As "artes da existência" devem ser entendidas como as práticas racionais e voluntárias pelas quais os homens não apenas determinam para si mesmos regras de conduta, como também buscam transformar-se e modificar seu ser singular, e fazer de sua vida uma obra que seja portadora de certos valores estéticos e que corresponda a certos critérios de estilo.(FOUCAULT, 2004, p. 198)
}

Periódico Horizontes - USF - Itatiba, SP - Brasil - e019038 
suma, os valores trágicos da Grécia clássica nos soam absurdos, pois, como diante de tal existência, optar pela vida? Como diante da nulidade da vida, buscar a imortalidade do nome? Se o que mais apraz é o "não ser, nada ser" ou o "logo morrer" de onde retirar forças para viver esteticamente? Voltarei a estas questões...

\section{Deus morreu...}

A outra provocação da qual parto é a concepção de Nietzsche de que deus está morto, muita tinta já foi vertida sobre a temática a morte de deus, de Heidegger a Jung, passando por Deleuze, Derrida, Foucault, Escola de Frankfurt, Sartre. Raros foram os leitores de Nietzsche que não se debruçaram sobre este tema.

Porém como sabemos Nietzsche não inaugura esta pretensão de fim de deus e do absoluto, antes do filósofo do martelo - apenas para constar como exemplo - Spinoza já havia retirado toda transcendência do absoluto, voltando o mesmo para a pura imanência, da mesma forma que Feurbach retirou a divindade dos céus e a devolveu ao homem.

A morte de deus é emblemática para nossa época, basta lembrar que na década de 90, logo após a derrubada do muro de Berlin, uma pichação na Alemanha Oriental correu o mundo, ela dizia "Nietzsche está morto, assinado Deus". Esta é uma das maiores provas que Nietzsche atingiu seu objetivo, ao diagnosticar a morte de deus e nos acusar do seu assassinato, o espírito nietzschiano continua espezinhando nossa época, chamando a atenção para o mais infame dos crimes, nos questionando "Como nos consolar, a nós assassinos entre os assassinos"? (NIETZSCHE, 2012, p.138). Por isso a necessidade de apontar o diagnosticador da morte de deus como morto. Sim, morto fisicamente, mas seu nome imortalizou-se na história do pensamento.

Deleuze afirma que Nietzsche: “Fez doze ou treze versões da morte de Deus para não se falar mais disso, para torná-la um acontecimento cômico". (DELEUZE, 2010, p.145). Meu propósito não é apontá-las, mas destacar duas delas, uma presente na obra Assim falou Zaratustra e outra na A Gaia Ciência. A primeira passagem se encontra no prólogo, quando Zaratustra logo após seu retiro vem ao encontro dos homens e encontra um velho santo, depois de um certo diálogo ao se despedir do velho, Zaratustra se pergunta: "Como será possível que este velho santo em sua floresta, ainda não soube que Deus está morto?" (NIETZSCHE, 2011, p.13).

$$
\text { Periódico Horizontes - USF - Itatiba, SP - Brasil - e019038 }
$$


A outra passagem é a famosa cena do louco no mercado, onde em plena manhã acendia uma lanterna e perambulava pelo mercado indagando a todos "onde está deus", depois de muito perguntar vaticina “(...) deus está morto, deus continua morto. E nós o matamos!" (NIETZSCHE, 2012, p.138).

É importante observar que Nietzsche não se diz assassino de deus, o que ele faz é um diagnóstico do ocidente e observou que o ocidente está assentado em dois pressupostos: os valores cristãos e a razão esclarecida; de um lado os valores de transcendência, além-mundo, compaixão e caridade, de outro, a recusa de qualquer tutela à razão, a repulsa por qualquer preconceito e superstição, a crença de que a razão é a melhor guia neste mundo tenebroso.

Para Nietzsche o entrechoque destes dois pilares resulta no fim de deus, pois o processo de iluminação da razão que se iniciou na Grécia clássica e teve seu ápice no iluminismo, dissipou as trevas da crença, nos restando apenas nas palavras do Teeto de Platão: a "crença, verdadeira e justificada" - Edmund Gettier vai destruir isso na década de 60 do século passado ${ }^{6}$, mas isso é outro assunto.

O pressuposto básico da morte de deus em Nietzsche implica na dissolução, derrocada, destruição, descrença no absoluto, pois o absoluto - enquanto acabado em si mesmo, como forma que se autosustenta, aquilo que subsiste por si, autojustificado, possui um valor intrínseco - se fundamenta em deus, se a razão esclarecida matou deus, então não há mais absoluto.

Sendo assim não há nada para além do humano no qual possamos nos refugiar, nem Paraíso, Valhalla, Campos Elíseos, muito menos Eldorados, sequer superação da violência, Sociedade sem classes, Consciência crítica, Autonomia, Liberdade, Esperança etc., qualquer refúgio destes é pura muleta metafísica, ou seja, um apoio existencial que utilizamos para não encararmos a tragicidade da vida.

Não havendo absoluto ainda podemos nos refugiar na razão esclarecida, nem tudo está perdido, ledo engano, muito pelo contrário, a razão é puro niilismo, pois a razão esclarecida parte de um pressuposto que nega o corpo e afirma uma pretensa autodeterminação da vontade a partir da racionalidade, ou seja, a mesma razão que matou deus, ressuscitou o absoluto como sua pretensão.

\footnotetext{
${ }^{6}$ Artigo: "É a crença verdadeira justificada um conhecimento"? Publicado por Edmund Gettier em 1963.

Periódico Horizontes - USF - Itatiba, SP - Brasil - e019038
} 
Porém não só Nietzsche demonstrou que nossa racionalidade está encharcada de pulsões, forças e valores, além de não ser autodeterminada, como também Freud vai falar do inconsciente enquanto força que determina essa racionalidade e até mesmo Marx vai nos dizer do efeito da ideologia nesta pretensa racionalidade livre. Nem razão esclarecida, nem absoluto, o que nos resta? Apenas o niilismo... voltarei a esta questão.

\section{Nascemos para sofrer...}

O outro diagnóstico do qual parto é a reflexão autobiográfica de Thomas Bernhard em sua obra Origem. Nesta obra o autor não poupa críticas a sua época, seus professores, sua família e a sociedade em que vive. Relatando uma infância vivida nos limites da existência. Dividido entre um avô que idolatra; um pai que nunca conheceu; um padrasto que não o registrou; um tio que viveu a margem da lei e uma mãe que quando olhava para ele via apenas o amante que a abandonou. Sendo estas as falas de sua mãe que "feriam a alma" do autor quando criança: "Você era tudo o que me faltava ou Você é a minha infelicidade, Eu quero que você vá para o inferno!, Você destruiu minha vida!, Você é culpado de tudo!, Você vai me matar!, Você é um nada, tenho vergonha de você!, Você é um inútil como seu pai! (...)” (BERNHARD, 2006, p.33, grifos do autor).

Eis o retrato da sua infância, vivida sob o pensamento abissal do suicídio. Conforme relata, este pensamento era uma constante, a tal ponto de em determinadas épocas não se passar um único dia em que não dedicasse horas a este pensamento, o que resultou em parcas tentativas frustradas de suicídio, pois o mesmo se via como covarde demais para por fim a aquela existência vazia:

[...] era covarde demais para me suicidar de fato, além de demasiado curioso em relação a tudo, a vida toda tive uma curiosidade descarada, o que sempre impediu que me suicidasse, teria me matado mil vezes caso essa minha curiosidade descarada não me houvesse retido sobre a face da terra. (BERNHARD, 2006, p.449).

Seu único alento era a idolatria de um avô filósofo e escritor que abominava toda mundaneidade da vida vulgar e refugiava-se no intento - fracassado - de construir uma obra magna depois de ter escrito vários livros sem grande sucesso. "Foi só por amor a meu avô que

$$
\text { Periódico Horizontes - USF - Itatiba, SP - Brasil - e019038 }
$$


não me matei na infância; não fosse isso, teria sido mais fácil para mim, afinal o mundo não passava de uma carga inumana, que, havia anos, não fazia senão ameaçar me sufocar". (BERNHARD, 2006, p.92).

Dada essas questões não resulta surpresa observar como o autor retrata nossa chegada neste mundo:

\begin{abstract}
Somos gerados, mas não criados ou educados; depois de nos terem gerado, nossos genitores investem contra nós com toda a sua estupidez, com todo o seu desamparo destruidor, e já nos três primeiros anos de vida arruínam o novo ser, do qual não sabem nada, a não ser, se tanto, que o produziram sem pensar, de forma irresponsável, não sabem que, tendo assim procedido, cometeram o maior dos crimes. Com ignorância e vileza absolutas, nossos genitores, isto é, nossos pais, nos põem no mundo e, feito isso, não conseguem lidar conosco, todas as suas tentativas fracassam, eles desistem logo, mas sempre tarde demais, sempre e somente quando já nos destruíram faz tempo, uma vez que naqueles três primeiros anos de vida - os anos decisivos, dos quais, porém nossos genitores nada sabem, nada querem saber, nada podem saber, porque durante séculos tudo se fez em prol dessa sua terrível ignorância - já nos destruíram e aniquilaram com sua ignorância, destruíram e aniquilaram sempre para a vida toda, porque a verdade é que, neste mundo, só lidamos com pessoas destruídas e aniquiladas em seus primeiros anos, aniquiladas para a vida toda por seus genitores, ou seja, por pais ignorantes, vis e nada esclarecidos (BERNHARD, 2006, p.171).
\end{abstract}

Assim prossegue o autor destilando uma percepção desalentadora da existência, falando dos pais como criminosos que investem contra as crianças com o único propósito de torná-las infelizes, a educação materna recebida em casa pode ser resumida em: "Ela me castigava, mas não me educou" (BERNHARD, 2006, p.39).

Como também os professores idiotizados que projetam o sadismo de uma existência medíocre no maltrato dos estudantes, "Aqueles professores não eram senão doentes cujo estado doentio atingia seu ápice nas aulas, só estúpidos ou doentes ou, melhor, só estúpidos e doentes dão aula no ginásio, uma vez que o que ensinam e despejam na cabeça de suas vítimas todo dia não é mais que estupidez e doença [...]" (BERNHARD, 2006, p.204).

Assim como o governo que propositalmente imbecializa seu povo para que o mesmo permaneça sempre como está. As sociedades que não possuem interesse em esclarecer seus membros, pois o esclarecimento dos mesmos acarretaria na aniquilação da sociedade etc.

Ao pensar a escola o autor relata perplexo como o movimento aniquilador das Periódico Horizontes - USF - Itatiba, SP - Brasil - e019038 
individualidades e do humano segue um trajeto ininterrupto, mudando quando muito apenas de nome, pois em última instância tudo prossegue absolutamente igual, com o único propósito de dizimar as singularidades, criando seres amorfos, tristes e perturbados. "[...] encarava a escola ainda instintivamente como aquilo que hoje, com plena clareza de entendimento, ela é para mim: uma instituição aniquiladora da mente e do espírito" (BERNHARD, 2006, p.191).

Ao observar em sua infância como os elementos nacionais socialistas foram substituídos por elementos católicos o autor assevera: "No fundo não havia diferença nenhuma entre o sistema nacional-socialista e o católico, tratava-se apenas de uma nova camada de tinta e de novas designações para tudo, os efeitos e consequências permaneciam os mesmos" (BERNHARD, 2006, p.183). Ao voltar para a escola, finda a guerra, o autor observa perplexo como foi fácil e rápido substituir as fotos de Hitler por imagens de Jesus e ao invés das crianças entoarem canções nacionais socialistas, agora entoam hinos de louvores a Deus, nem mesmo os horários e a estrutura hierárquica havia sido alterada, apenas a simbologia mudou e nada, além disso.

\section{O que nos resta? Niilismo...}

Diante de tal análise da existência, da sociedade, da família e da escola o que nos resta? Ecoa a fala de Sileno e ao que tudo indica 25 séculos depois ainda não há muitas opções apenas "não ser, nada ser" ou "logo morrer", pois segundo o diagnóstico de Nietzsche, solapamos até mesmo nosso último refúgio, o absoluto. Que valores podem advir de uma existência massacrada desta forma? Que alternativa nos resta diante de tal desalento?

Bernhard não vê alternativa e mergulha no niilismo, onde os valores são dissolvidos e nenhum valor é alçado a condição de critério para a existência: “Minha principal característica hoje é a indiferença, ou seja, a consciência da equivalência entre tudo que passou, tudo que é e tudo que será. Não existem valores elevados, mais elevados ou supremo, isso tudo acabou" (2006, p.316).

Este niilismo dissolve até mesmo o valor da própria existência, pois o autor compreende que "A vida não é mais que o cumprimento de uma pena, disse a mim mesmo, e é preciso suportar o cumprimento desta pena. Por toda vida. O mundo é uma prisão com pouquíssima liberdade de movimento" (BERNHARD, 2006, p.434). 
Assim a dissolução dos valores leva a uma concepção pessimista da vida "Desde o primeiro momento, o ser humano foge da vida que conhece desde esse primeiro momento, foge porque a conhece, e em direção a morte, que não conhece. Todos nós fugimos a vida inteira sempre na mesma direção" (BERNHARD, 2006, p.310).

Nietzsche poucas décadas antes de Bernhard diagnosticou o futuro do ocidente como um mergulho no niilismo, para além do niilismo em sua forma clássica da dissolução dos valores e o seu desalento desesperador da ausência de qualquer valor - como se apresenta nos escritos de Bernhard - Nietzsche compreende o niilismo como o alçar a condição de valor o nada, utilizar como critério de valor questões transcendentes e observar o naufragar dos objetos da nossa fé, eis o niilismo em sua forma nietzschiana.

Nietzsche define o niilismo como: “[...] falta de meta; falta de resposta ao 'por que'? Que significa niilismo? - o fato de que os valores supremos se desvalorizam" (NIETZSCHE, 2013, p.289). Esta ausência/relativização dos valores, esse nada querer, denominado niilismo, não tem uma significação unívoca na obra do pensador do martelo.

O niilismo na obra de Nietzsche segundo Peter Pál Pelbart (2006) se configura de quatro formas, sendo três formas imobilizantes: negativo, reativo e passivo e uma forma que possibilita a ação e a criação, o niilismo ativo. Estas quatro formas podem ser traduzidas em dois sintomas, as três formas imobilizantes seriam o sintoma da decadência e aversão pela existência, já o niilismo ativo é a expressão de um aumento de força, condição para um novo começo, uma transvaloração.

De um lado temos o niilismo negativo, um tipo de niilismo que partindo de um certo pessimismo diante da existência, reduz a vontade de potência à negação, este agir depreciativo diante da vida gestou a metafísica, os valores teológicos, morais, racionais e tudo mais o que nega a vida e o mundo sensível.

Os valores transcendentes do niilismo negativo se apresentam de forma dogmática, hierarquizando, dicotomizando, determinando e regulamentando a existência, a vida e o mundo a partir da negação do transitório, da aparência e do devir, afirmando uma suposta essência, teleologia e racionalidade.

Por outro lado, temos o niilismo reativo reagindo ao niilismo negativo, nesta reação se propõe a substituir os primeiros valores por outros, criando assim o imperativo moral, o

$$
\text { Periódico Horizontes - USF - Itatiba, SP - Brasil - e019038 }
$$


desenvolvimento, a felicidade, o progresso, cultura etc. Esses valores desprovidos da primeira transcendência exemplificam as promessas da Modernidade e do iluminismo, onde o homem moderno que assassinou deus, permanece envolto pela sombra do deus morto, pois almeja substituir deus.

Esta recusa da verdade anterior cria uma nova verdade, apesar da ação destruidora e criativa empreendida, a nova verdade não refutou os vícios da primeira verdade, a crença na verdade foi reforçada a partir de uma nova verdade.

Por fim o niilismo passivo denotando o cansaço e a frustração do humano que cético e decepcionado pelas promessas da racionalidade e da modernidade, pensa que nada mais vale a pena. O nojo e a repulsa de uma existência absurda, repetitiva e sem sentido paralisa a sua ação, para este niilista nada mais há que se fazer ou esperar.

Eis o niilismo de Bernhard, não há mais verdade, valores ou determinações A crítica aos valores voltou-se contra si mesma, nada mais resta, todas as verdades são recusadas, até mesmo as verdades que afirmam a existência.

Voltando as provocações iniciais, observamos que com estas três formas de niilismo, não há como diante do absurdo da existência optar pela vida, muito menos diante da nulidade da vida, buscar a imortalidade do nome, cabendo então a solução de Sileno "não ser, nada ser" ou o "logo morrer", pois se não há nem mesmo razão esclarecida, ou absoluto, o que nos resta é apenas este niilismo desesperador.

Porém há uma quarta forma de niilismo, depois de ter mergulhado profundamente nos três primeiros niilismos a alma que não almeja paz, mas que busca sempre a sua superação, utiliza a expansão de força do niilismo para transvalorar, este é o niilismo ativo.

O niilismo ativo, este desdobrar-se dos outros tipos de niilismo, resulta em um sonoro dizer sim à vida e a busca por realizar uma ação efetiva sobre à mesma, o convite niilista à destruição também é um convite a criação, pois novos valores só nascem após à destruição dos valores antigos.

A atitude ativa diante do niilismo, busca a transvaloração, a criação, reabilitar a aparência, construir novas verdades, porém agora consciente que estas verdades são temporárias, apenas hábitos breves, buscando não se comprometer rapidamente, mas estar livre para criar. 


\section{Educação, a transvaloração do niilismo...}

O niilismo enquanto esse pressuposto que os valores supremos se desvalorizam, resultando em um nada alçado à condição de valor, se expressa em muitas formas, desde a filosofia, religião, moral, estética, movimento social, literatura e até mesmo educação, aliás, a educação é um excelente reflexo do niilismo, onde observamos os sintomas dos valores imobilizantes do niilismo.

Na educação o niilismo negativo repercute em uma crença desmedida em algo que se situa etereamente para além da mundaneidade - esperança, emancipação, consciência, critica, libertação etc. - a espera na realização de algo que nunca se realiza, a fé em um futuro a partir da não aceitação do presente, o desprezo pela vida como ela se apresenta. Utopias pedagógicas que resultam em pífios movimentos, cujas ações repercutem muito mais na crítica do presente do que na construção do mesmo.

Já o Niilismo reativo reflete a substituição dos primeiros valores transcendentes por questões práticas, a não realização da utopia pedagógica primeiramente sonhada, nos leva a imaginar que questões científicas comprovadas seriam o nosso alento na educação, desta forma nos voltamos para métodos inovadores, exigimos mais verba, elaboramos intrincadas técnicas pedagógicas, realizamos minuciosas análises de rendimento, propomos currículos amplos ou focados em temas específicos etc., esta ênfase na prática, no cotidiano, no fazer, não deixa de ser uma simples resposta a volatilidade do primeiro niilismo.

Esta reação resulta em niilismo por manter os vícios da primeira proposta: a crença em uma solução única, passível de aplicar a todos, a fé, porém desta vez a fé se volta para a imanência e novamente os resultados se esvanecem em nada, pois a crença na verdade permanece, mesmo que a verdade tenha descido dos céus, agora ela manifesta-se na materialidade, no humano, em última instância, nós deicidas substituímos o deus assassinado.

O nosso desejo de normatizar o humano, regular a vida e fixar o devir existencial, associado a falibilidade e muitas vezes a impossibilidade deste processo desemboca em um ceticismo radical - o Niilismo passivo - quando negamos o processo educativo, desesperançados, sem perspectivas, isso tudo refletido nos nossos determinismos "foi sempre assim e sempre será assim".

Professores desmotivados, estudantes alheios a importância da formação, salas 
esvaziadas de formação e atulhadas de gente. Nesta trajetória do niilismo chegamos no momento em que o nada se torna valor, dissolvendo os valores outrora alçados a valores supremos, toda ação resulta em nada.

A questão permanece: Como construir um processo pedagógico para além destes niilismos, um processo pedagógico que resulte em um outro tipo de niilismo, um atravessar destes valores imobilizantes que resulte em um niilismo ativo, promovendo a ação e criando os valores e a existência a partir da experimentação da vida.

Em última instância esta formação atuaria como uma contraeducação visando possibilitar ao estudante insurgir-se contra a formação recebida. No caminho de tornar-se o que se é, esta resistência seria necessária, pois, "Conforme nos educam hoje, adquirimos primeiro uma segunda natureza, e a possuímos quando o mundo diz que chegamos a maturidade, emancipados, tornados úteis" (NIETZSCHE, 2008, p.222). Bernhard compactua com esse diagnóstico ao observar que:

[...] esse ser soterrado por inteiro por seus genitores ou pais precisou de trinta anos para remover o entulho sob o qual esses genitores ou pais o enterraram, para somente então tornar-se o ser humano que decerto teria sido desde o início, aquele que seus genitores ou pais, pais ou genitores enterraram sob o próprio lixo emocional e intelectual de séculos (2006, p.174).

Esta educação pensada por Nietzsche dissolve a autoridade do educador, pois parte do compromisso inalienável do educando de educar a si mesmo, muitas vezes contra a educação recebida, buscando transvalorar / transmutar os valores, movendo-os para além ou através, deslocando, retirando do lugar usual os valores impostos.

\section{Valores em tempos de morte de deus...}

Deus: a entificação do suprassensível, o fiador do bem, a garantia da unicidade do sentido, o guia da teleologia, o critério externo da verdade, a base da moral, a fixidez que estanca o devir existencial, o fundamento da justiça, o absoluto para o qual aponta a mundaneidade; este deus está morto, irremediavelmente morto, inexoravelmente extinto, no lugar da certeza, da promessa, do alento, da esperança, da utopia, da crença, o que nos resta? Uma lacuna, uma

$$
\text { Periódico Horizontes - USF - Itatiba, SP - Brasil - e019038 }
$$


ruptura, uma brecha, um vazio descomunal; vida e apenas vida, fria e insólita, pois durante todo nosso percurso racional consideramos a vida falsa, ilusória, fugaz, sem valor.

Voltando a provocação deste texto: Que valores são possíveis diante de um diagnóstico tão pessimista da existência humana? Pois, se não há transcendência, nem absoluto, muito menos quaisquer "muletas metafísicas" que garantam consolo para esta existência. O que nos resta para aceitar o desafio nietzschiano de encarar a tragicidade da existência rindo, sem muletas metafísicas?

Resta unicamente a nós mesmos, o humano, destituído de qualquer pretensão absoluta. A existência necessita ser valorada a partir da condição humana, do instante, do momento, ou seja, o critério de valor é a vida, humana demasiadamente humana.

Não a vida como totalidade metafísica, mas a vida que se apresenta no instante do vivido. A vida que se expande e se dissipa diante do mover da existência. A vida no interior do devir existencial. A vida e apenas a vida.

Dos três niilismos imobilizantes ao niilismo afirmativo, podemos observar uma trajetória do niilismo onde o mesmo atinge seu ápice, completa-se ao dissolver-se em criação, o nada torna-se a possibilidade de afirmar, pois o niilista ativo vivencia o devir existencial.

No devir, no nada, no caos da vida, na mundaneidade da existência, no instante, é aqui que se exerce o potencial destrutivo do niilismo ativo, resultando na afirmação da vida, a leveza da ausência de fundamento, descrença na fixidez e dissolução da verdade implica em um afirmar o existir que nega os valores absolutos, mas não abre mão dos valores.

Compreendo os valores como crenças interiorizadas que traduzem as preferências mais básicas de um tipo humano, onde a partir dos valores o humano hierarquiza a vida fixando o que sente como benéfico ou nocivo, pois: "O ponto de vista do valor é o ponto de vista de condições de conservação e expansão que concerne às formações complexas com relação relativa de vida no interior do devir" (NIETZSCHE, 2013, p.27).

Valorar a existência utilizando como critério a vida é - nas palavras de Nietzsche - aceitar que a vida é vontade de potência e somos um múltiplo vital e pulsional, um conjunto de forças movidos pela vontade de potência, e isto o que comumente denominamos humano busca sempre por mais vontade de potência, toda potência, visa mais potência, o que nos resta é utilizar como valor tudo aquilo que nos propicia buscar mais potência. 
Ou seja, nada além ou fora do humano, aliás, nem sequer algo interior ao humano, mas simplesmente o humano e suas condições de existência, sendo assim não há valores previamente definidos, pois não há a menor possibilidade de definir o que é a vontade de potência de um humano, devido ao caráter fluído tanto do humano quanto da vontade de potência. O todo orgânico, pulsional e conflitante denominado humano, não persiste em uma única configuração por tempo suficiente para diagnosticarmos sua vontade de potência.

Para finalizar questiono: possuímos força para suportarmos esta incompletude?

\section{Referências}

BERNHARD, T. Origem. Trad. Sergio Tellaroli. São Paulo: Companhia das letras. 2006.

DELEUZE, G.; GUATTARI, F. O Anti-Édipo: capitalismo e esquizofrenia. Trad. Luiz B. L. Orlandi. São Paulo: Ed. 34, 2010.

FOUCAULT, M. Ditos e Escritos V: Ética, Sexualidade, Política, Rio de Janeiro, Editora Forense Universitária Ltda., 2004.

HOMERO. Odisseia. Trad. Frederico Lourenço. Lisboa: Cotovia, 2003.

HOMERO. Ilíada. Trad. Carlos Alberto Nunes. São Paulo: Ediouro, 2001.

NIETZSCHE, F. W. O nascimento da tragédia ou helenismo e pessimismo. Trad. Jacó Guinsburg. São Paulo: Companhia das letras. 2007.

NIETZSCHE, F. W. Aurora: reflexões sobre os preconceitos morais. Trad. Mario D. F. Santos. Petrópolis-RJ: Vozes. 2008.

NIETZSCHE, F. W. Assim falou Zaratustra: um livro para todos e para ninguém. Trad. Paulo César de Souza. São Paulo: Companhia das Letras. 2011.

NIETZSCHE, F. W. A gaia ciência. Trad. Paulo César de Souza. 1. ed. São Paulo: Companhia das Letras. 2012.

NIETZSCHE, F. W. Fragmentos póstumos: 1885 - 1887, vol. VI. Trad. Marco Antônio Casanova. Rio de Janeiro: Forense Universitária. 2013.

PELBART, P. P. Travessias do niilismo. In: V. FEITOSA, C.; BARRENECHEA, M. A.; PINHEIRO, P. (Orgs.). Nietzsche e os gregos - arte memória e educação: assim falou Nietzsche. Rio de Janeiro/Brasília: Editora DP\&A; Faperj; Unirio/Capes. 2006, p. 205 - 228.

$$
\text { Periódico Horizontes - USF - Itatiba, SP - Brasil - e019038 }
$$


Recebido em julho de 2018.

Aprovado em março de 2019. 